\title{
AIR FUEL RATIO STUDY FOR MIXTURE OF BIOGAS AND HYDROGEN ON MILD COMBUSTION
}

\author{
M.M. Noor ${ }^{1,2}$, Andrew P. Wandel ${ }^{1}$ and Talal Yusaf ${ }^{2,3}$ \\ ${ }^{1}$ Computational Engineering and Science Research Centre, \\ School of Mechanical and Electrical Engineering, \\ University of Southern Queensland (USQ), Australia \\ ${ }^{2}$ Faculty of Mechanical Engineering, \\ Universiti Malaysia Pahang (UMP), 26600 Pekan, Pahang, Malaysia \\ Email: muhamad@ump.edu.my \\ Phone: +6094245255; Fax: +6094246222 \\ ${ }^{3}$ National Centre for Engineering in Agriculture, \\ USQ, Australia
}

\begin{abstract}
Air fuel ratio (AFR) is an important parameter to indicate the combustion quality. Lower AFR will result in unburned hydrocarbons (UHC) that harm the environment. This paper discusses the simulation of AFR for the moderate or intense low oxygen dilution combustion using bluff-body burner. A low calorie biogas fuel of $50 \%$ methane, $20 \%$ hydrogen and $30 \%$ carbon dioxide were used in this simulation. The AFR evaluated based on the UHC produced and measured in the exhaust gas composition. Stoichiometric AFR produced zero UHC and zero excess oxygen measured in the exhaust gas. UHC in the exhaust gas is a waste of fuel and is possible to create unwanted combustion at an unwanted location. The study found that at AFR 4:1, almost zero UHC was detected in the exhaust gas pipe and exhaust gas recirculation pipe.
\end{abstract}

Keywords: Air fuel ratio; MILD combustion; biogas; hydrogen; exhaust gas recirculation.

\section{INTRODUCTION}

Demand for clean and low cost energy is become a global issue due to the depletion of fossil fuel and environmental pollution concern [1,2]. Combustion of fossil fuel still plays a major role for today energy generations $[3,4]$. Fuel cost for the heating process is accounted for up to $10 \sim 15 \%$ of total production cost [5]. Both fuel efficiency and lean combustion are very critical to reduce the total production cost and directly reduce the end product cost. There are possible long-term solutions which are high thermal efficiency combustion technology and biogas fuel produced from local feedstock. MILD combustion is one of the new combustion technologies to increase thermal efficiency and reduce combustion pollution emission [6-8]. This technology is also known as flameless oxidation (FLOX) [9, 10]. The MILD combustion is getting more attention from the scientific community $[11,12]$ and labelled as part of the dilution combustion technology [13]. It emits low nitrogen oxides $\left(\mathrm{NO}_{\mathrm{x}}\right)$ and carbon monoxide $(\mathrm{CO})$ pollutant emissions, and high thermal [14-16]. When using the regenerator to recycle the waste heat of flue gases, the thermal efficiency of MILD combustion can increase by $30 \%$, while reducing 
NOx emissions by 50\% [15]. By using biogas as a fuel [17-20] or low calorific value (LCV) gas, $\mathrm{CO}_{2}$ emitted by the combustion will be utilised by biomass, which is the source of biogas.

The effect of air fuel ratio (AFR) to the combustion efficiency has been studied for MILD combustion [21, 22] and hydrogen fueled internal combustion engine [23, 24]. The result shows that the performance of combustion is very much affected by AFR used. Too low or too high AFR will reduce the combustion efficiency. The industrial heating community always uses a high AFR setting, which is also lean combustion. Lean combustion reduces the fuel cost and unwanted unburned hydrocarbons (UHC) gases that are released into the atmosphere. The requirement of MILD combustion is the oxygen dilution and the mixtures preheat. One of the economical ways to achieve this is by utilising the exhaust gas. Exhaust gas recirculation (EGR) was previously used for MILD combustion [25-27] and has the role of preheating the oxidiser and diluting the oxygen. The combustion chamber needs to be enclosed in order to collect the flue gas, and it is utilised as EGR. EGR flows downward to mix with incoming fresh air. The EGR ratio is based on the dilution ratio that is required by the combustion. The EGR ratio is the volume of flue gas used as EGR over total flue gas. MILD combustion can be achieved when the oxygen level is between 3 13\% [11].

The purpose of this study is to simulate and check the AFR on LCV gas mixed with hydrogen and the effect on unburned methane $\left(\mathrm{CH}_{4}\right)$ and hydrogen $\left(\mathrm{H}_{2}\right)$ for the open burner MILD combustion. A mixture of 50\% methane, $20 \%$ hydrogen and $30 \%$ carbon dioxide was used to make the biogas. The result is then compared to a previous study using a different composition of fuel.

\section{COMPUTATIONAL MODELLING}

Computational fluid dynamics (CFD) modelling has been successful in numerically solving many engineering problems [28-32]. There are many researchers [33-37] who have successfully studied the MILD and flameless combustion using the numerical simulation method. The open burner MILD combustion was modelled (Figure 1) using ANSYS14.5 design modeler and simulates using FLUENT 14.5 with the size of $1.9 \mathrm{~m}$ height and $0.6 \mathrm{~m}$ width. This model is a modified version of the previous [38]. Typical data for the burner is shown in Table 1.

Table 1. Typical data for burner and combustion chamber

\begin{tabular}{|c|c|}
\hline Item & Data \\
\hline Fuel & $50 \%$ methane, $20 \%$ hydrogen and $30 \%$ carbon dioxide \\
\hline Oxidiser & Atmospheric air and syntactic air at room temperature \\
\hline Fuel inlet & $1 \times 78.5 \mathrm{~mm}^{2}$ \\
\hline Air inlet & $4 \times 78.5 \mathrm{~mm}^{2}$ \\
\hline Chamber size & Diameter 600 mm, Height $860 \mathrm{~mm}$ \\
\hline EGR & 4 EGR with $1962.5 \mathrm{~mm}^{2}$ each inlet \\
\hline Mesh method & $\begin{array}{l}\text { Tetrahedrons (patch conforming method) with } 111,975 \text { nodes } \\
\text { and } 501,831 \text { elements }\end{array}$ \\
\hline Radiation model & $\begin{array}{l}\text { Discrete ordinate (DO) model. Absorption coefficient: } \\
\text { Weighted sum of gray gas (WSGGM) model }\end{array}$ \\
\hline
\end{tabular}


The fuel and air injection nozzles were designed as a bluff body to help the mixing process. The fuel nozzle was in the middle with the diameter of $1 \mathrm{~mm}$, and annulus air nozzle around the fuel nozzle with the opening size of $1,570 \mathrm{~mm}^{2}$. The combustion chamber consists of four EGR pipe with inner diameter of $1962.5 \mathrm{~mm}^{2}$ each. The MILD combustion simulation involved the solution of the chemical reactions, turbulent flows, heat transfer and species transport. Non-premixed combustion with chemical equilibrium and non-adiabatic energy treatment was used. In this work, the Reynolds-Averaged Navier-Stokes (RANS) equations, together with a realisable k- $\varepsilon$ turbulence model [39] (that was developed based on standard k- $\varepsilon$ turbulence model [40] are solved. The discrete ordinate (DO) radiation model [41] and the absorption coefficient of the weighted sum of gray gas (WSGGM) model is used in this work.

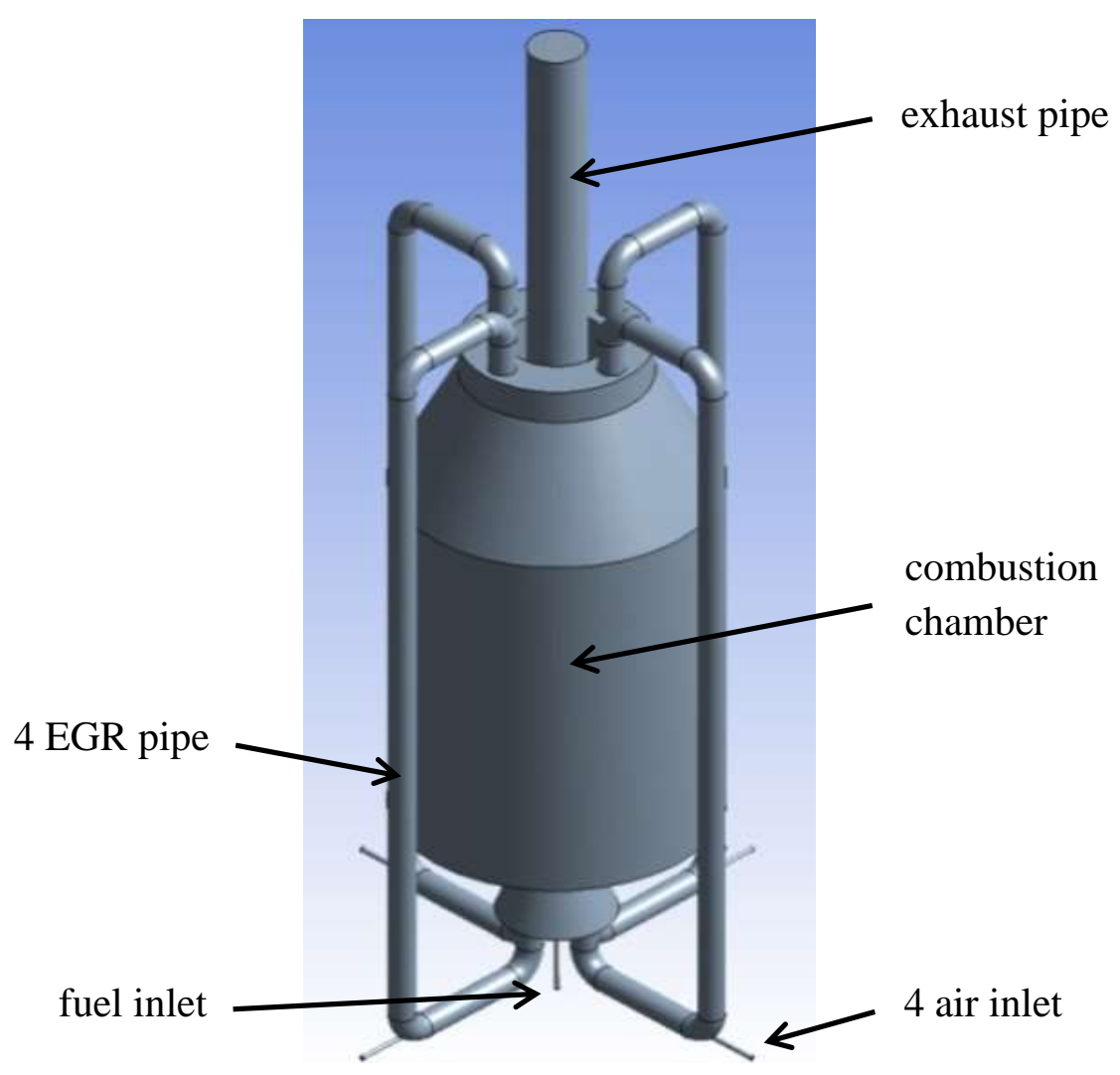

Figure 1. 3D burner geometry with boundary conditions

The method of meshing is tetrahedrons (patch conforming) with advanced sizing function of proximity and curvature and detail setting, as in Table 2. The mesh inflation for the near the wall was five layers with a growth rate of $20 \%$. The nozzle mesh element refinement was used for air, fuel inlet, air fuel nozzle and EGR inlet and outlet. Figure 2 shows the meshing elements of 1,477,322 and nodes count of 490,406. The maximum skewness is 0.904 , which is below the allowable limit of 0.98 . The maximum skewness must be below 0.98 or the solution will easily become divergence error and will not converge as desired [42]. Fuel enters the burner fuel inlet at the bottom of the burner with $10 \mathrm{~mm}$ diameter and $78.5 \mathrm{~mm}^{2}$ inlet area. If the velocity of the fuel injected is 1 $\mathrm{m} / \mathrm{s}$, the volume flow rate for the fuel is $7.85 \times 10^{-5} \mathrm{~m}^{3} / \mathrm{s}$. Air is injected through four inlets at the side of EGR with $10 \mathrm{~mm}$ diameter each. Total air inlet diameter is $314 \mathrm{~mm}^{2}$. If the 
air is injected at $1 \mathrm{~m} / \mathrm{s}$, the air volume flow rate is $3.14 \times 10^{-3} \mathrm{~m}^{3} / \mathrm{s}$. The ratio of air and fuel nozzle in this study is 5.0. This ratio was based on the previous study that gave AFR of 5.0 to achieve almost zero UHC and unburned hydrogen in the EGR pipe [43]. The initial air and fuel nozzle ratio in the previous study was based on the methane air mass fraction ratio which 9.5:1.

Table 2. Mesh setting details.

\begin{tabular}{lc}
\hline \multicolumn{1}{c}{ Sizing } & Setting \\
\hline Advance Size Function & On: Proximity and Curvature \\
Relevance Center & Fine \\
Initial Size Seed & Active Assembly \\
Smoothing & High \\
Transition & Slow \\
Span Angle Center & Fine \\
\hline
\end{tabular}

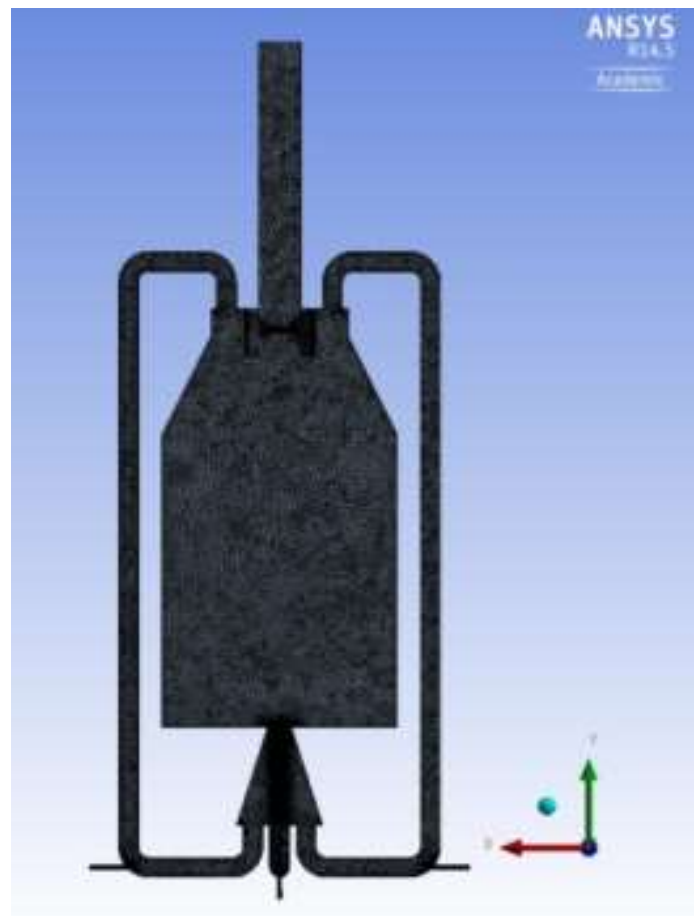

Figure 2. Model after meshing in 2D.

This burner was fuelled by the mixture of methane with hydrogen and carbon dioxide. The fuel mole fraction for this work to produce LCV is given in Table 3. The air mole fraction is $21.008 \% \mathrm{O}_{2}$ and $78.992 \% \mathrm{~N}_{2}$. In the author's earlier paper, the different LCV composition was used with an amount of ethane, propane and butane. In the laboratory for the experimental work, it is not practical to use seven types of gas (Table 3 ), as the supply and mixing process becomes too complicated and not economical. Thus, three types of gases are analysed in this paper: methane, hydrogen and carbon dioxide. The difference is that the previous study used $86.64 \%$ of hydrocarbon mixed with $13.36 \% \mathrm{CO}_{2}$, and this paper used $70 \%$ of hydrocarbon and $30 \%$ of $\mathrm{CO}_{2}$. 
Table 3. LCV gas composition

\begin{tabular}{lcc}
\hline \multicolumn{1}{c}{ Gas } & This paper & Previous study [38] \\
\hline Methane $\left(\mathrm{CH}_{4}\right)$ & 0.50 & 0.5344 \\
Hydrogen $\left(\mathrm{H}_{2}\right)$ & 0.20 & 0.3000 \\
Carbon dioxide $\left(\mathrm{CO}_{2}\right)$ & 0.30 & 0.1336 \\
Nitrogen $\left(\mathrm{N}_{2}\right)$ & 0.00 & 0.0130 \\
Ethane $\left(\mathrm{C}_{2} \mathrm{H}_{6}\right)$ & 0.00 & 0.0170 \\
Propane $\left(\mathrm{C}_{3} \mathrm{H}_{8}\right)$ & 0.00 & 0.0010 \\
Butane $\left(\mathrm{C}_{4} \mathrm{H}_{10}\right)$ & 0.00 & 0.0010 \\
\hline
\end{tabular}

The oxygen in the oxidiser stream will be diluted by EGR to the required level. The AFR was calculated based on the air and fuel velocity injected to the burner. Due to the different size of the inlet diameter between air and fuel, AFR is calculated on volume flow rate of air divided by fuel volume flow rate. The AFR and air velocity used in this study ranges from 1.0 to $6.5 \mathrm{~m} / \mathrm{s}$ and 20 to $120 \mathrm{~m} / \mathrm{s}$. The total injected volume flow rate into a burner is between $0.0057 \mathrm{~m}^{3} / \mathrm{s}$ and $0.0176 \mathrm{~m}^{3} / \mathrm{s}$. The details of AFR and volume flow rate are shown in Table 4.

Table 4. Air and fuel volume flow rate and AFR

\begin{tabular}{|c|c|c|c|c|c|}
\hline $\begin{array}{l}\text { Air velocity } \\
(\mathrm{m} / \mathrm{s})\end{array}$ & $\begin{array}{l}\text { Fuel } \\
\text { velocity } \\
(\mathrm{m} / \mathrm{s})\end{array}$ & $\begin{array}{c}\text { Air volume } \\
\text { flow rate } \\
\left(\mathrm{m}^{3} / \mathrm{s}\right)\end{array}$ & $\begin{array}{c}\text { Fuel volume } \\
\text { flow rate } \\
\left(\mathrm{m}^{3} / \mathrm{s}\right)\end{array}$ & $\begin{array}{c}\text { Total volume } \\
\text { flow rate } \\
\left(\mathrm{m}^{3} / \mathrm{s}\right)\end{array}$ & AFR \\
\hline 20 & 100 & 0.0028 & 0.0028 & 0.0057 & 1.0 \\
\hline 30 & 100 & 0.0043 & 0.0028 & 0.0071 & 1.5 \\
\hline 40 & 100 & 0.0057 & 0.0028 & 0.0085 & 2.0 \\
\hline 50 & 100 & 0.0071 & 0.0028 & 0.0099 & 2.5 \\
\hline 60 & 100 & 0.0085 & 0.0028 & 0.0114 & 3.0 \\
\hline 65 & 100 & 0.0092 & 0.0028 & 0.0121 & 3.3 \\
\hline 70 & 100 & 0.0099 & 0.0028 & 0.0128 & 3.5 \\
\hline 75 & 100 & 0.0107 & 0.0028 & 0.0135 & 3.8 \\
\hline 80 & 100 & 0.0114 & 0.0028 & 0.0142 & 4.0 \\
\hline 100 & 125 & 0.0142 & 0.0035 & 0.0177 & 4.0 \\
\hline 100 & 120 & 0.0142 & 0.0034 & 0.0176 & 4.2 \\
\hline 90 & 100 & 0.0128 & 0.0028 & 0.0156 & 4.5 \\
\hline 100 & 100 & 0.0142 & 0.0028 & 0.0170 & 5.0 \\
\hline 90 & 82 & 0.0128 & 0.0023 & 0.0151 & 5.5 \\
\hline 120 & 100 & 0.0170 & 0.0028 & 0.0199 & 6.0 \\
\hline 100 & 77 & 0.0142 & 0.0022 & 0.0164 & 6.5 \\
\hline
\end{tabular}

\section{RESULTS AND DISCUSSION}

The effect of AFR on the concentration of the unburned $\mathrm{CH}_{4}$ and $\mathrm{H}_{2}$ was evaluated using a modelled open burner (Figure 1). The simulated results in Figure 3 show that the AFR of 1.0 gives the highest unburned $\mathrm{CH}_{4}$ at the stoichiometric value 4.17. The initial value of mole fraction for $\mathrm{CH}_{4}$ and $\mathrm{H}_{2}$ is 0.5 and 0.20 , respectively. The combustion process can be written in a general hydrocarbon stoichiometric combustion equation: 


$$
C_{n} H_{m}+\left(n+\frac{m}{4}\right)\left(O_{2}+3.76 N_{2}\right) \rightarrow n C O_{2}+\frac{m}{2} H_{2} O+3.76\left(n+\frac{m}{4}\right) N_{2}
$$

The stoichiometric combustion equation (Eq. (1)) with 50\% EGR for low calorific value gas consists of mole fraction of 50\% methane, $20 \%$ hydrogen and $30 \%$ carbon dioxide. From total flue gas, $50 \%$ will flow back to the chamber and lower the oxygen level in the oxidiser stream.

$$
\begin{gathered}
\left(0.5 \mathrm{CH}_{4}+0.2 \mathrm{H}_{2}+0.3 \mathrm{CO}_{2}\right)+\left(1.1 \mathrm{O}_{2}+4.14 \mathrm{~N}_{2}\right)+\left(0.8 \mathrm{CO}_{2}+1.2 \mathrm{H}_{2} \mathrm{O}+4.14 \mathrm{~N}_{2}\right) \rightarrow \\
\left(1.6 \mathrm{CO}_{2}+2.4 \mathrm{H}_{2} \mathrm{O}+8.28 \mathrm{~N}_{2}\right)
\end{gathered}
$$

This equation is for the equivalent ratio of 1.0. If the equivalent ratio is reduced, the fuel is reduced and AFR increases. In this study, when AFR is equal to 4.0, unburned $\mathrm{CH}_{4}$ and $\mathrm{H}_{2}$ mole fraction in the EGR pipe is almost zero. The stoichiometric AFR for this fuel composition is 4.17. Compared to the previous study [38] with different burner design and different LCV mixing (Table 3), UHC and unburned hydrogen reaches almost zero when AFR is 5.0. The stoichiometric AFR for this fuel composition is 3.61. Figure 3 shows the comparison of these results and shows that when AFR $=4.0$ and 5.0, the $\mathrm{CH}_{4}$ and $\mathrm{H}_{2}$ mole fraction in EGR were almost zero.

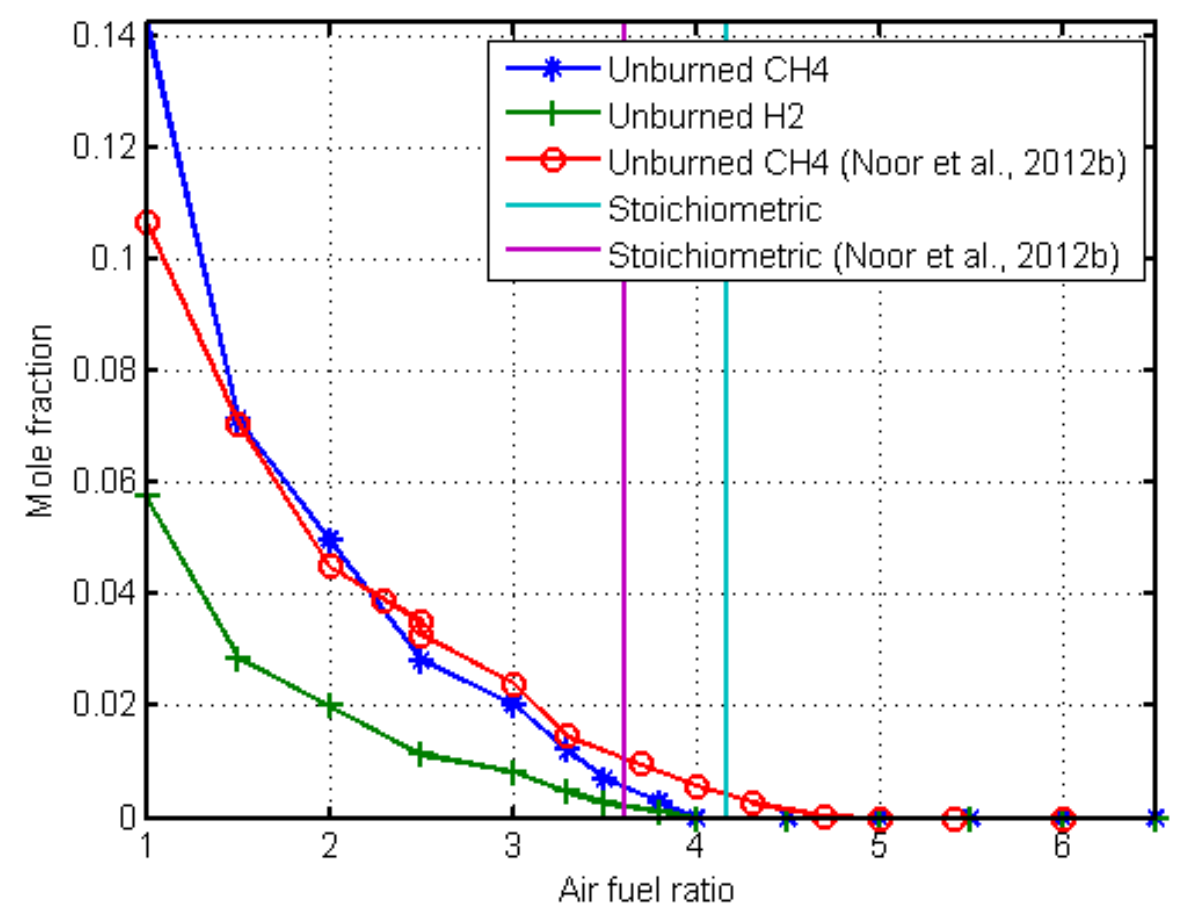

Figure 3. Unburned of $\mathrm{CH}_{4}$ and $\mathrm{H}_{2}$ for AFR.

The result in Figure 4 shows that the UHC in flue gas flows through an exhaust opening and EGR pipe. Figure 4 shows a reaction from the mixing of the hot UHC and $\mathrm{O}_{2}$ - which is supplied from the fresh air - that happens outside of the combustion chamber such as in the EGR pipe. The reaction is unfavourable. Figure 5 shows a desired combustion with 100\% methane and oxygen consumed by the combustion process, which achieves MILD combustion state. Figures 6 and 7 shows the mole fraction of methane and oxygen respectively. Both methane and oxygen were $0 \%$ in the 
combustion chamber and EGR pipe. For oxygen mole fraction in the Figure 7, there is a small amount of oxygen on the top of the exhaust pipe. This condition occurred due to the back flow of the exhaust pipe. A small back flow does not have a significant effect on the combustion process since the exhaust pipe is long enough to avoid back flow of fresh air into the combustion chamber.
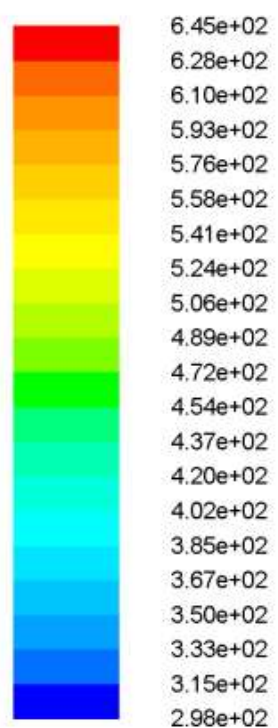

$2.98 \mathrm{e}+02$

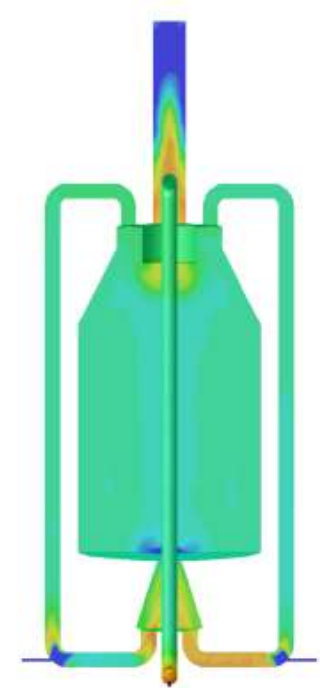

(a)

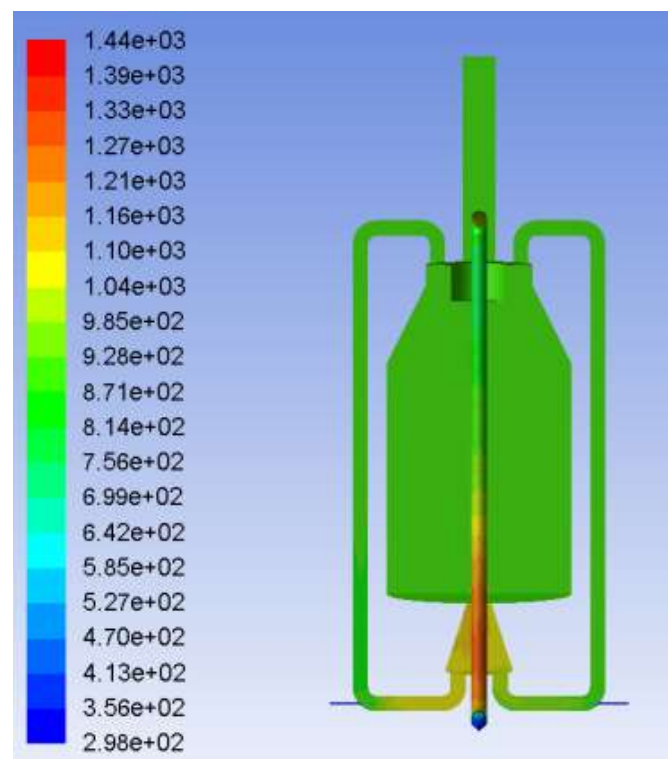

(b)

Figure 4. Temperature contour (Kelvin) when unwanted burning in EGR pipe due to unburned $\mathrm{CH}_{4}$ and $\mathrm{H}_{2}$ (a) in exhaust pipe (b) in EGR pipe

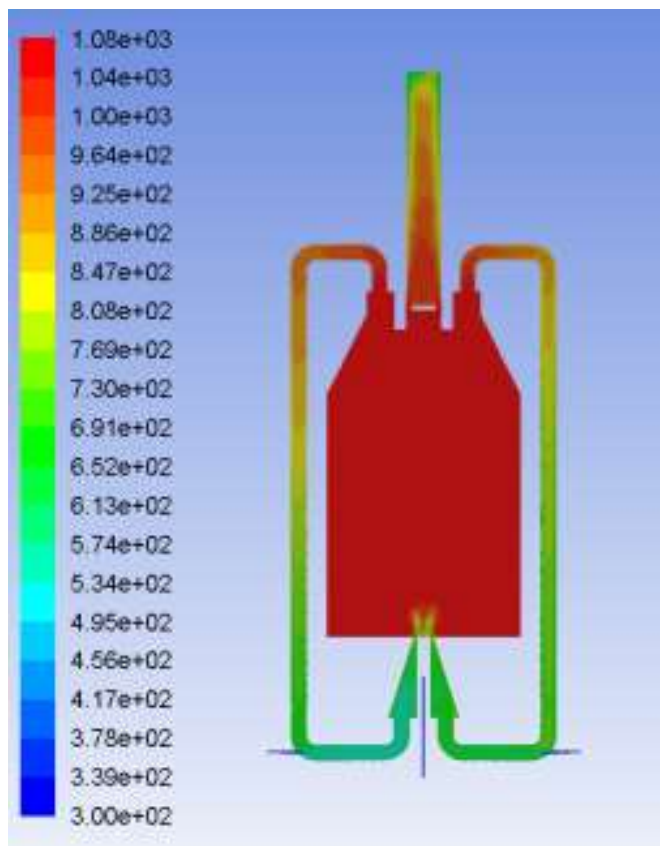

Figure 5. Cross section on temperature contour (Kelvin) when proper MILD combustion with fuel $100 \%$ consumed 


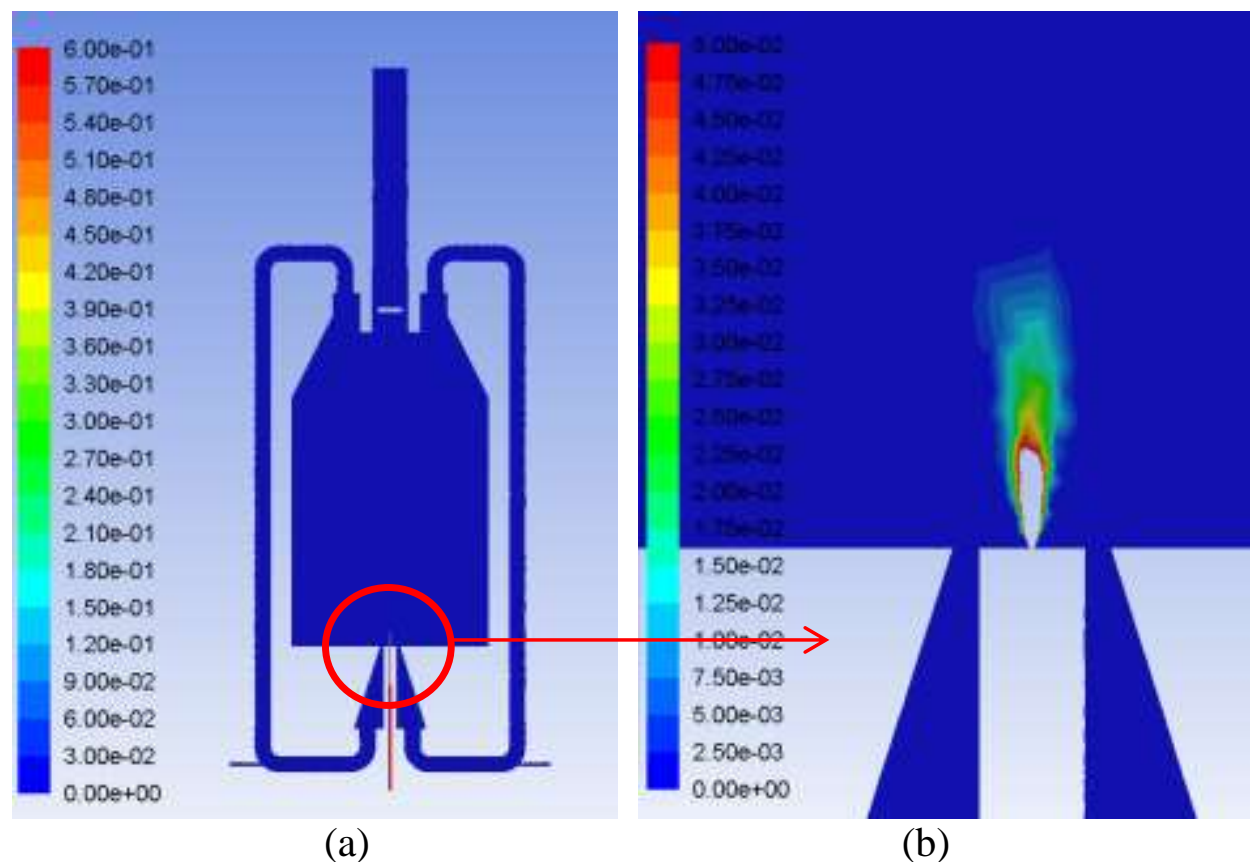

Figure 6. The mole fraction of methane in the combustion chamber and EGR pipe; (a) is for the full domain (with a mole fraction range between 0 and 0.6), (b) for a zoomed-in region (with a mole fraction range between 0 and 0.05 )

(a)

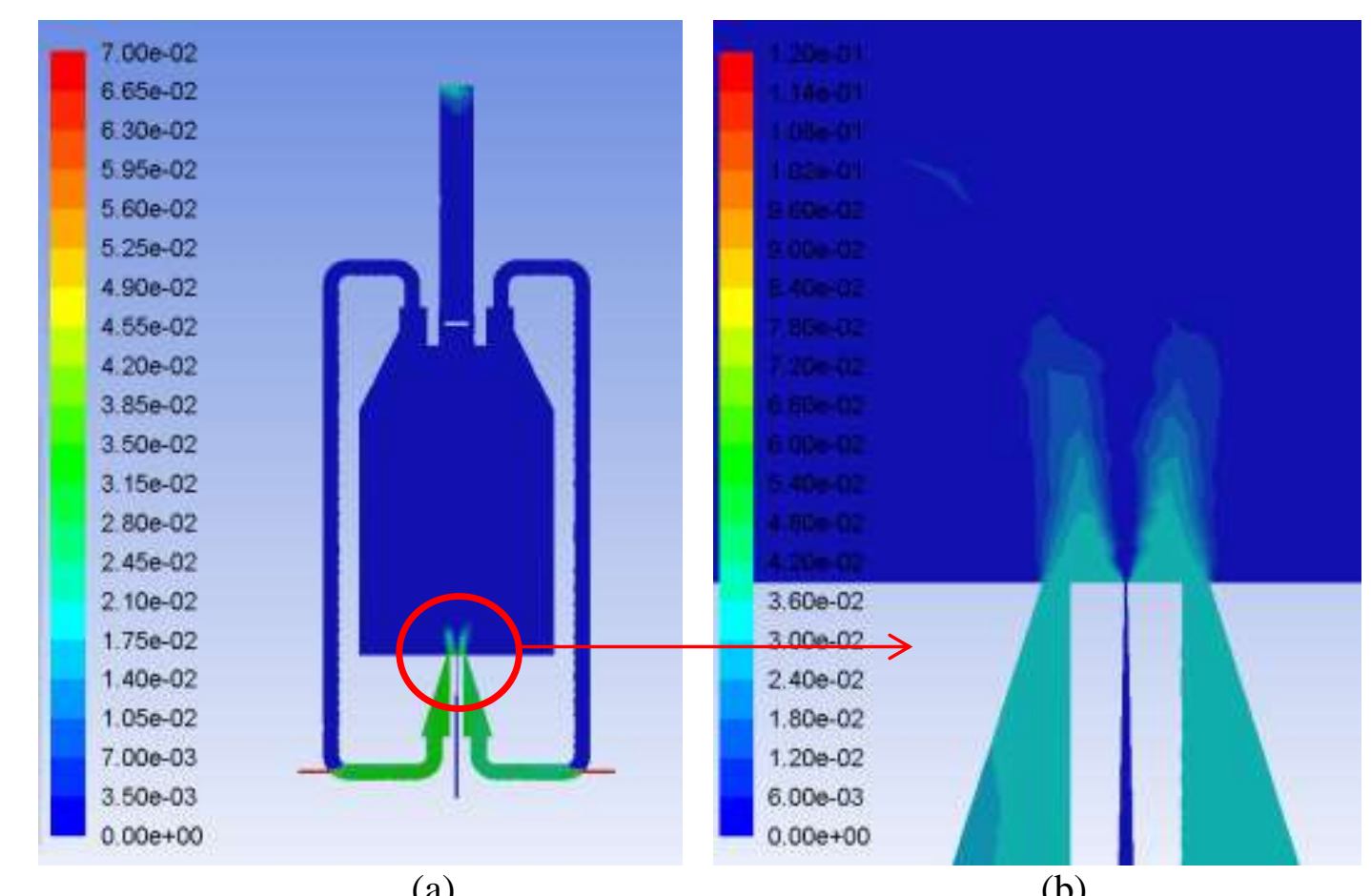

\section{(b)}

Figure 7. The mole fraction of oxygen in the combustion chamber and EGR pipe; (a) is for the full domain (with a mole fraction range between 0 and 0.07), (b) for a zoomedin region (with a mole fraction range between 0 and 0.012 )

The MILD combustion regime can be achieved either fuelled by natural gas or biogas, and the performance of a burner remaining constant. In both cases, pollution 
emissions are very low, $\mathrm{NO}_{\mathrm{x}}$ emissions are below $3 \mathrm{ppm}$ and $\mathrm{CO}$ emissions are below 16 ppm [17]. Dally et al. [44] was successful in achieving MILD combustion by using sawdust as a fuel. Biogas gives $2 \%$ lower efficiencies compared to natural gas. This condition should be compensated by the reduction of greenhouse gases when using biogas as a fuel. These results indicate that the flameless combustion regime can be achieved with different fuels compositions [17].

\section{CONCLUSIONS}

The present paper concludes that AFR for biogas mixed with $20 \%$ hydrogen gives lower AFR than the $30 \%$ hydrogen. For biogas mixed with $20 \%$ hydrogen, the achieved AFR is 5:1; and for biogas mixed with $30 \%$ hydrogen, the achieved AFR is $4: 1$. The simulation results deduce that unburned fuel or UHC will be in the exhaust gas when not enough oxygen is supplied to the combustion chamber. Air and fuel plays an important role to complete the combustion process. In the combustion process, to consume all the fuel, AFR must be higher than 4:1. Otherwise, the combustion process will produce unburned methane and hydrogen. This condition is called rich fuel combustion. UHC is a waste of fuel, and it is part of environmental pollution.

\section{ACKNOWLEDGMENTS}

The authors would like to thank University of Southern Queensland (USQ), Ministry of Education, Malaysia (MOE) and Universiti Malaysia Pahang (UMP) for providing financial support and laboratory facilities.

\section{REFERENCES}

[1] Shafiee S, Topal E. When will fossil fuel reserves be diminished? Energy Policy. 2009;37:181-9.

[2] Al-lwayzy S, Yusaf T. Chlorella protothecoides Microalgae as an Alternative Fuel for Tractor Diesel Engines. Energies. 2013;6:766-83.

[3] Noor M, Wandel AP, Yusaf T. Mild combustion: the future for lean and clean combustion. International Review of Mechanical Engineering. 2013;8:251-7.

[4] Al-lwayzy S, Yusaf T, Al-Juboori R. Biofuels from the Fresh Water Microalgae Chlorella vulgaris (FWM-CV) for Diesel Engines. Energies. 2014;7:1829-51.

[5] USDOE. Roadmap for process heating technology. 2001.

[6] Cavaliere A, de Joannon M. Mild Combustion. Progress in Energy and Combustion Science. 2004;30:329-66.

[7] Dally BB, Riesmeier E, Peters N. Effect of fuel mixture on moderate and intense low oxygen dilution combustion. Combustion and Flame. 2004;137:418-31.

[8] Christo FC, Dally BB. Modeling turbulent reacting jets issuing into a hot and diluted coflow. Combustion and Flame. 2005;142:117-29.

[9] Wunning JG. Flammlose Oxidation Von Brennstoff Mit Hochvorgewarmter Luft. Chem-Ing-Tech. 1991;63:1243-5.

[10] Wünning JG. Flammlose oxidation von brennstoff. Aachen: Mainz; 1996.

[11] Noor M, Wandel AP, Yusaf T. A review of MILD combustion and open furnace design consideration. International Journal of Automotive and Mechanical Engineering. 2012;6:730-54. 
[12] De Joannon M, Cavaliere A, Donnarumma R, Ragucci R. Dependence of autoignition delay on oxygen concentration in mild combustion of high molecular weight paraffin. Proceedings of the Combustion Institute. 2002;29:1139-46.

[13] Torresi M, Camporeale S.M., Fortunato B. RS, M. M, A. S. Diluted combustion in a arodynamically staged swirled burner fueled by diesel oil. Process and Technology for Sustainable Energy. 2010:1-8.

[14] Dally BB, Karpetis AN, Barlow RS. Structure of turbulent non-premixed jet flames in a diluted hot coflow. Proceedings of the Combustion Institute. 2002;29:1147-56.

[15] Tsuji H, Gupta AK, Hasegawa T. High temperature air combustion: CRC Press, Boca Raton, Forida; 2003.

[16] Dearden L.M., Massingham J.D., M. P, Wild P.N., A. W, L.T. Y. Controlling NOx emissions from high-temperature air-preheat burners with air-staging. Journal of the Institute of Energy 1996;69:23-30.

[17] Colorado AF, Herrera BA, Amell AA. Performance of a Flameless combustion furnace using biogas and natural gas. Bioresource Technology. 2010;101:24439.

[18] Colorado AF, Medwell PR, Dally BB. LCV fuels emissions of turbulent nonpremixed jet flames under MILD combustion conditions. Australian Combust Symposium. Uni. of Queensland, Australia2009.

[19] Hosseini SE, Wahid MA. Biogas utilization: Experimental investigation on biogas flameless combustion in lab-scale furnace. Energy Conversion and Management. 2013;74:426-32.

[20] Cardona CA, Amell AA. Laminar burning velocity and interchangeability analysis of biogas/C3H8/H2 with normal and oxygen-enriched air. International Journal of Hydrogen Energy. 2013;38:7994-8001.

[21] Noor M, Wandel AP, Yusaf T. Numerical study of oxygen dilution and temperature distribution of biogas combustion in Bluff-body MILD burner. Proceedings of the 7th Australian Combustion Symposium (ACS 2013). 2013:299-303.

[22] Kumar S, Paul PJ, Mukunda HS. Investigations of the scaling criteria for a mild combustion burner. Proceedings of the Combustion Institute. 2005;30:2613-21.

[23] Rahman M, Hamada KI, Noor M, Kadirgama K, Bakar RA, Rahim M. Heat transfer characteristics in exhaust port for hydrogen fueled port injection engine: a transient approach. Advanced Materials Research. 2011;152:1909-14.

[24] Hamada KI, Rahman M, Noor M, Kadirgama K, Bakar RA. Influence of Engine Speed and Injection Timings on In-Cylinder Heat Transfer for Port Injection Hydrogen Fueled Engine. NCMER. 2010;2:3-4.

[25] Katsuki M, Hasegawa T. The science and technology of combustion in highly preheated air. Symposium (International) on combustion. 1998;27:3135-46.

[26] Minamoto Y, Dunstan TD, Swaminathan N, Cant RS. DNS of EGR-type turbulent flame in MILD condition. Proceedings of the Combustion Institute. 2013;34:3231-8.

[27] Lee C-L, Jou C-JG. Integrated methods to improve efficiency of furnace burning recovered tail gas. International Journal of Hydrogen Energy. 2012;37:6620-5.

[28] Wandel AP, Smith NSA, Klimenko AY. Implementation of multiple mapping conditioning for single conserved scalar. Second International Conference on CFD, Springer-Verlag. 2003:789-90. 
[29] Dally BB, Fletcher DF, Masri AR. Flow and mixing Fields of turbulent bluffbody jets and flames Combustion Theory and Modelling. 1998;2:193-219.

[30] Davidson DL. The role of computational fluid dynamics in process industries,. The Bridge. 2002;32:9-14.

[31] Najiha MA, Rahman MM, Kamal M, Yusoff AR, Kadirgama K. Minimum quantity lubricant flow analysis in end milling processes: a CFD approach. Journal of Mech Eng and Sciences. 2012;3:340-5.

[32] Najiha MA, Rahman MM, Yusoff AR, Kadirgama K. Investigation of flow behaviour in minimum quantity lubrication nozzle for end milling processes. International Journal of Automotive and Mechanical Engineering. 2012;6:76876.

[33] Mardani A, Tabejamaat S. Effect of hydrogen on hydrogen-methane turbulent non-premixed flame under MILD condition. International Journal of Hydrogen Energy. 2010;35:11324-31.

[34] Mardani A, Tabejamaat S, Ghamari M. Numerical study of influence of molecular diffusion in the Mild combustion regime. Combustion Theory and Modelling. 2010;14:747-74.

[35] Mardani A, Tabejamaat S, Hassanpour S. Numerical study of $\mathrm{CO}$ and $\mathrm{CO} 2$ formation in $\mathrm{CH} 4 / \mathrm{H} 2$ blended flame under MILD condition. Combustion and Flame. 2013;160:1636-49.

[36] Galletti C, Parente A, Tognotti L. Numerical and experimental investigation of a mild combustion burner. Combustion and Flame. 2007;151:649-64.

[37] Parente A, Galletti C, Tognotti L. Effect of the combustion model and kinetic mechanism on the MILD combustion in an industrial burner fed with hydrogen enriched fuels. International Journal of Hydrogen Energy. 2008;33:7553-64.

[38] Noor M, Wandel AP, Yusaf T. A preliminary study of control parameters for open furnace MILD combustion using CFD. Proceedings of the 2nd Malaysian Postgraduate Conference (MPC 2012). 2012:46-60.

[39] Shih TH, Liou WW, Shabbir A, Yang Z, JZ A new k-e eddy-viscosity model for high Reynolds Number turbulent flows-model development and validation Computers and Fluids 1995;24:227-39.

[40] Launder BE, Spalding DB. The numerical computation of turbulent flows. Computer Methods in Applied Mechanics and Engineering. 1974;3:269-89.

[41] Chui EH, Raithby GD. Computation of radiant heat transfer on a nonorthogonal mesh using the finite-volume method. Numerical Heat Transfer, Part B: Fundamentals. 1993;23:269-88.

[42] Noor MM, Wandel AP, Yusaf T. Simulation of biogas combustion in MILD burner. Journal of Mechanical Engineering and Sciences. 2014:995-1013

[43] Noor M, Wandel AP, Yusaf T. The modelling of the effect of air fuel ratio on unburned hydrocarbons for MILD combustion. Proceedings of the 2nd Malaysian Postgraduate Conference (MPC 2012). 2012:159-63.

[44] Dally BB, Shim SH, Craig RA, Ashman PJ, Szego GG. On the burning of sawdust in a MILD combustion furnace. Energy and Fuel. 2010;24:3462-70. 